\title{
Malakoplakia of the Kidney Extending to Case Malakoplakia of the Kidney Extending to Report the Descending Colon in a Patient with Secondary Adrenal Insufficiency: A Case Report
}

\author{
Soo Jin Jung, Hee Cheol Kang*, Jun Jeong Choi ${ }^{1}$
}

Department of Family Medicine, Yonsei University College of Medicine, Seoul, ${ }^{1}$ Department of Pathology, Yonsei University Wonju College of Medicine, Wonju, Korea

Malakoplakia is an uncommon but distinctive type of chronic granulomatous inflammation that occurs most commonly in the genitourinary tract, especially the urinary bladder. Most patients have associated conditions characterized by some degree of immunosuppression, as seen in solid-organ transplants, autoimmune diseases requiring steroid use, chemotherapy, chronic systemic diseases, alcohol abuse and poorly controlled diabetes. We report an unusual case of the renal malakoplakia that involved the perirenal space, extending to the descending colon in a 65-year-old Korean woman with secondary adrenal insufficiency and diabetes mellitus.

Keywords: Malakoplakia; Adrenal Insufficiency; Diabetes Mellitus; Korea

\section{INTRODUCTION}

Malakoplakia is a rare chronic inflammatory disease that occurs most commonly in the genitourinary tract, especially the urinary bladder. Most patients have associated conditions characterized by some degree of immunosuppression, as seen in solid-organ transplants, autoimmune diseases requiring steroid use, chemotherapy, chronic systemic diseases, alcohol abuse

Received: June 9, 2011, Accepted: September 8, 2011

${ }^{*}$ Corresponding Author: Hee Cheol Kang

Tel: 82-2-2228-2332, Fax: 82-2 362-2473

E-mail: kanghc@yuhs.ac

Korean Journal of Family Medicine Copyright (c) 2011 The Korean Academy of Family Medicine (a) This is an open-access article distributed under the terms of the Creative Commons Attribution Non-Commercial License (http://creativecommons.org/licenses/by-nc/3.0) which permits unrestricted noncommercial use, distribution, and reproduction in any medium, provided the original work is properly cited. and poorly controlled diabetes. ${ }^{1)}$ Despite some characteristic histological features including the presence of large histiocytes with clusters of Michaelis-Gutmann (MG) bodies, malakoplakia of the kidney is difficult to diagnose because of its rarity and varying histological pictures. ${ }^{2)}$ To our knowledge, there have been no case reports of malakoplakia of the kidney in a secondary adrenal insufficiency from Korea. Here, we report an unusual case of renal malakoplakia involving the perirenal space and extending to the descending colon in a 65-year-old Korean woman with secondary adrenal insufficiency and diabetes mellitus.

\section{CASE REPORT}

In March 2010, a 65-year-old woman was transferred from the National Police Hospital (NPH) to our facility, Shinchon Severance Hospital (Seoul, Korea) via the emergency room (ER), presenting with a decreased level of consciousness. According to her medical history, she had hypertension, diabetes mellitus for 10 years, recurrent cystitis, and degenerative arthritis. She 
had been taking dexamethasone ( $5 \mathrm{mg}$, once a day) for the degenerative arthritis for approximately five years up to the time of admission. Three weeks before the admission, she had been hospitalized at NPH due to drowsy mentality for 3 or 4 hours. On the day of admission at $\mathrm{NPH}$, she presented with a fever $\left(38.8^{\circ} \mathrm{C}\right)$ and dyspnea. The patient was given antibiotics (ceftriaxone and azithromycin) for 14 days, on suspicion of community-acquired pneumonia. Thereafter, her presenting symptoms were improved, but she complained of consistent pain in the left lower quadrant of the abdomen. Abdomen-pelvis computed tomography (CT) scan was performed, which showed the mass-like lesion in the left renal area suspecting abscess. While being treated with ciprofloxacin, she developed a decreased level of consciousness.

Upon physical examination on the day of the admission to our hospital, her initial vital signs were as follows: blood pressure $134 / 71 \mathrm{~mm} \mathrm{Hg}$, pulse rate 95 bits per minute, body temperature $36.4^{\circ} \mathrm{C}$, and respiration rate 18 breaths per minute. Her level of consciousness was drowsy. Her breathing sound was clear, and her heart sound was normal without any murmurs. There was no specific finding upon abdominal examination without peripheral edema. Laboratory studies had the following results (reference values): low sodium $(\mathrm{Na})$ levels of $112 \mathrm{mmol} /$ L (135.0-145.0), potassium (K) $3.4 \mathrm{mmol} / \mathrm{L}(3.5-5.5)$, chloride (Cl) $77.0 \mathrm{mmol} / \mathrm{L}(98-110)$, total $\mathrm{CO}_{2} 21.0 \mathrm{mmol} /$ L (24-30), low serum osmolality 240.0 mOsm (289.0$308.0)$, and normal urine osmolality 315.0 (50.0-1200). The thyroid function test was normal. Morning serum cortisol levels decreased to 7.1 (Table 1). Initial urinalysis results showed 3-5 white blood cells/high-power field and yeast-like organisms. In the radiological examination, there was no acute ischemic lesion in the brain magnetic resonance imaging and angiography with neck angiography (3D), and no specific finding on the chest $\mathrm{X}$-ray. Sodium replacement therapy for hypotonic euvolemic hyponatremia had been started from the day of admission. At that stage, secondary adrenal insufficiency due to exogenous steroid was suspected. A low dose adrenocorticotropic hormone ( $1 \mu \mathrm{g}$ cosynthropin) stimulation test was conducted to diagnose the secondary adrenal insufficiency. The stimulation test showed that there was adrenal insufficiency; basal level of cortisol $8.56 \mu \mathrm{g} /$ $\mathrm{dL}$, peak level during the hour-long test $13.94 \mu \mathrm{g} / \mathrm{dL}$ (Table 2). Steroid hormone (hydrocortisone sodium succinate; solucortef) was replaced.
Table 1. Results of laboratory analysis performed on the day of hospitalization.

\begin{tabular}{|c|c|c|}
\hline & Result & $\begin{array}{l}\text { Reference } \\
\text { range }\end{array}$ \\
\hline White blood cell (no./ $\mu \mathrm{L})$ & $7,160.0$ & $4,000-10,800$ \\
\hline Neutrophil (\%) & 57.5 & $40-74$ \\
\hline Lymphocyte (\%) & 25.3 & $19-48$ \\
\hline Monocyte (\%) & 13.1 & $3.3-9$ \\
\hline Eosinophil (\%) & 1.5 & $0-7$ \\
\hline Hemoglobin (g/dL) & 9.8 & $12.0-16.0$ \\
\hline Hematocrit (\%) & 29.2 & $37.0-47.0$ \\
\hline Erythrocyte sedimentation rate (mm/h) & 60.0 & $0.0-20.0$ \\
\hline C-reactive protein $(\mathrm{mg} / \mathrm{L})$ & 48.90 & $0-8$ \\
\hline D-dimer quantity (ng/mL) & 503.0 & $0-243$ \\
\hline Prothrombin time (s) & 15.3 & $9.8-13.4$ \\
\hline Prothrombin time (INR ) & 1.29 & $0.91-1.16$ \\
\hline aPTT (s) & 24.7 & $27.9-41.6$ \\
\hline Glucose (mg/dL) & 117.0 & $70-110$ \\
\hline Hemoglobin Alc* (\%) & 6.5 & $4.0-6.0$ \\
\hline Blood urea nitrogen $(\mathrm{mg} / \mathrm{dL})$ & 2.1 & $5.0-25.0$ \\
\hline Creatinine $(\mathrm{mg} / \mathrm{dL})$ & 0.89 & $0.50-1.40$ \\
\hline Sodium $(\mathrm{mmol} / \mathrm{L})$ & 112.0 & $135.0-145.0$ \\
\hline Potassium (mmol/L) & 3.4 & $3.5-5.5$ \\
\hline Chloride (mmol/L) & 77.0 & $98-110$ \\
\hline Total $\mathrm{CO}_{2}(\mathrm{mmol} / \mathrm{L})$ & 21.0 & $24-30$ \\
\hline Osmolality (mOsm) & 240.0 & $289.0-308.0$ \\
\hline Thyoid stimulating hormone $(\mu \mathrm{IU} / \mathrm{mL})$ & 1.73 & $0.35-5.50$ \\
\hline Free T4 (ng/dL) & 1.22 & $0.89-1.76$ \\
\hline T3 (ng/mL) & 1.49 & $0.6-1.8$ \\
\hline Cortisol* $\left.^{*} \mu \mathrm{g} / \mathrm{dL}\right)$ & 7.1 & \\
\hline Adrenocorticotropic hormone* (pg/mL) & 16.79 & \\
\hline Urine osmolality (mOsm) & 315.0 & $50.0-1,200$ \\
\hline Urine sodium (mmol/L) & 84.0 & \\
\hline Urine microalbumin (mg/dL) & 1.95 & $0-3.0$ \\
\hline
\end{tabular}

*Test performed on the day after hospitalization.

On the third day after admission, her general condition including clear consciousness was improved, with a normal level of serum sodium $(136 \mathrm{mmol} / \mathrm{L})$, and her steroid hormone dosage had been gradually tapered down and was maintained at $7.5 \mathrm{mg}$ 
Table 2. Results of low dose adrenocorticotropic hormone stimulation Test on the third day of hospitalization.

\begin{tabular}{lcccc}
\hline Hormone & Level at 0 min & Level at 15 min & Level at 30 min & Level at 60 min \\
\hline Cortisol $^{*}(\mu \mathrm{g} / \mathrm{dL})$ & 8.56 & 11.9 & 13.9 & 13.9 \\
\hline
\end{tabular}

*Reference range: $7.00-19.4$ in the morning, 2.00-9.00 in the afternoon.
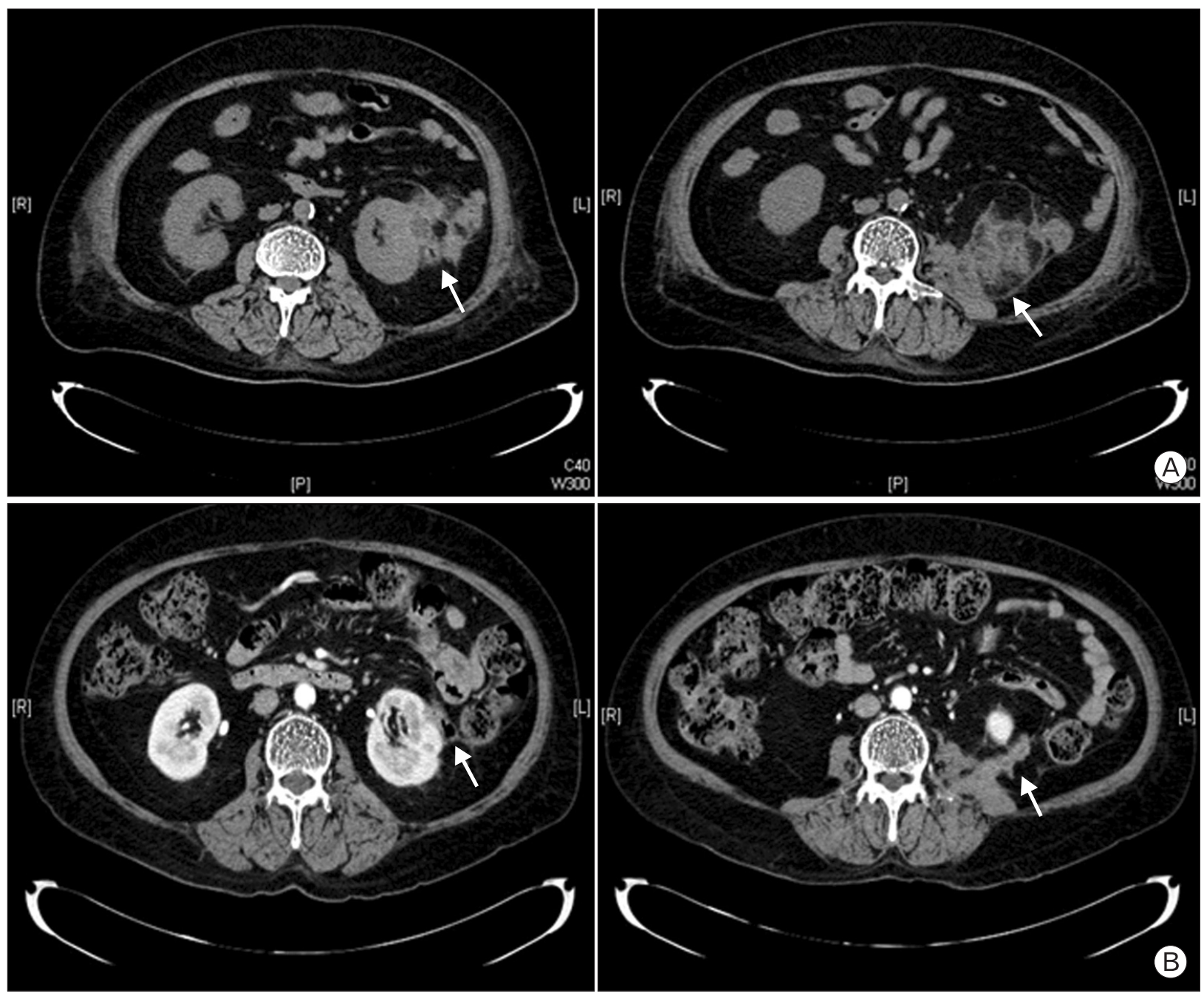

Figure 1. Abdomen-pelvic computed tomography (CT) scan. An abdomen-pelvic CT image obtained on the second day after admission (A) shows an ill-defined inflammatory lesion in the left kidney with multifocal abscess pockets in the left perirenal space, extending to the descending colon. An abdomen-pelvic CT image obtained after 4 months during readmission (B) shows the remaining ill-defined inflammatory lesion in the left kidney and descending colon involvement.

( $5 \mathrm{mg}, 2.5 \mathrm{mg}$ two times a day) of prednisolone acetate. However, the patient complained of myalgia, which was accompanied with leukocytosis (white blood cell count 13,650 $\mu \mathrm{g} / \mathrm{L}$ [neutrophil 84.9 $\%])$. Radiological reading of the abdomen-pelvic CT conducted on the second day after admission showed that there was an illdefined inflammatory lesion with multifocal abscess pockets in the left perirenal space, which was suspected of actinomycosis of the descending colon, extended to the left kidney (Figure 1A). Compared to the abdomen-pelvic CT finding performed outside, the lesion seemed to have decreased slightly in size. Urinalysis was repeated and showed many white blood cells per high-power field and yeast-like organisms, which was confirmed as yeast in the 

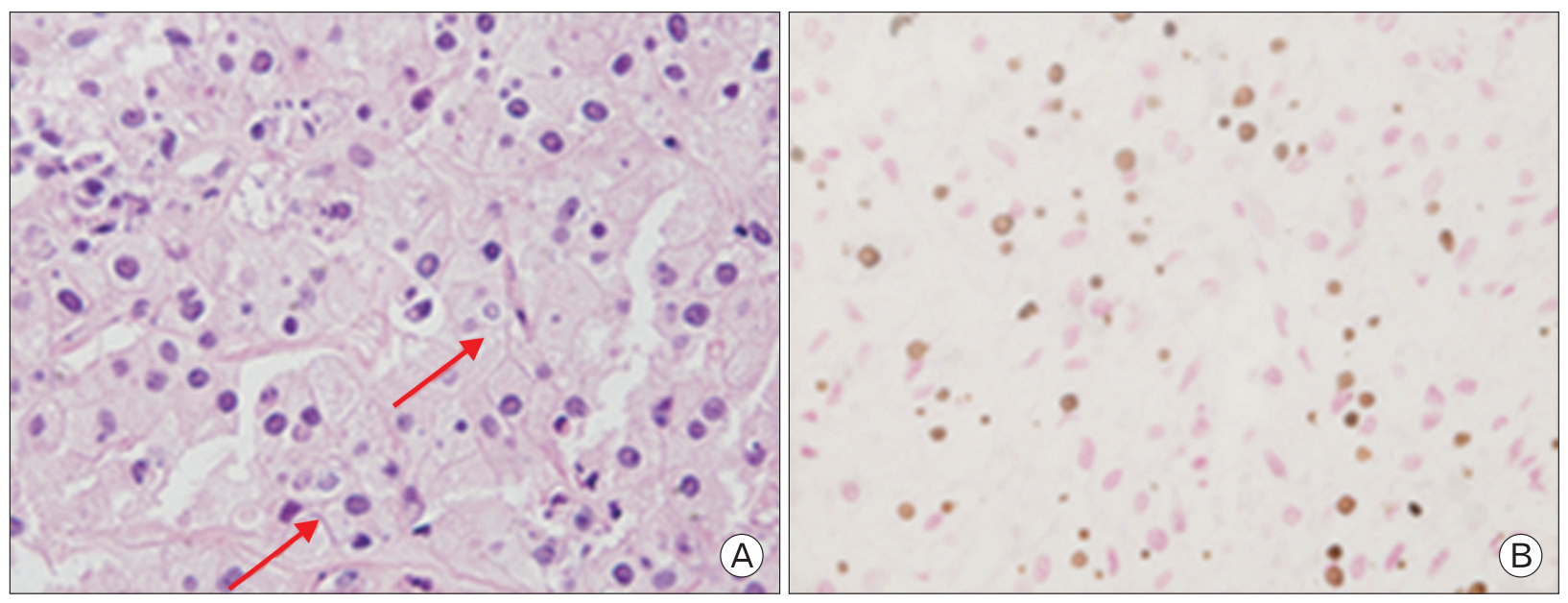

Figure 2. Renal biopsy (photomicrograph). (A) shows histiocytes with acellular basophilic precipitations (arrow) (H\&E, ×400). (B) shows concentric, acellular basophilic precipitation (a.k.a Michaelis-Gutmann bodies) demonstrating calcium deposition (von Kossa stain, $\times 400)$.

urine culture. Considering the laboratory and radiologic findings, intravenous antibiotic treatment was started (ubacillin 1,500 $\mathrm{mg}$ a day) for suspected actinomycosis. No specific lesion was found at the colonoscopy performed to confirm the diagnosis of actinomycosis.

On the 12th day after admission, we conducted an ultrasonography-guided renal biopsy. The histology of the lesion showed a collection of foamy histiocytes also known as von Hansemann cells with von-kossa stain positive spheres (MichelisGutmann body) (Figure 2). These findings are consistent with Malakoplakia. The patient presented dysuria and urgency, and antibiotic treatment was changed to oral ciprofloxacin (500 mg a day). On the 15th day after admission, she was discharged, as her presenting symptoms and laboratory findings were improved.

About 4 months after discharge, the patient was readmitted presenting with general weakness for one month. The findings of the abdomen-pelvic CT conducted upon readmission (Figure 1B) showed that the extent of the malakoplakia in the perirenal space had decreased since 9 week prior, as she had been taking the oral antibiotics. She has had follow-up in our outpatient clinic ever since, taking oral trimethoprim-sulfamethoxazole.

\section{DISCUSSION}

Malakoplakia is an uncommon but distinctive type of chronic granulomatous inflammation. Upon microscopic examination, malakoplakia is characterized by the presence of sheets of histiocytes with granular cytoplasm (von Hansemann cells) and the formation of intracellular bacterial inclusions called MichaelisGutmann bodies. ${ }^{3-7)}$

The pathogenesis is poorly understood, but it is thought to result from acquired bactericidal defects in macrophages occurring mostly in patients with chronic debility or immunosuppression, a kidney transplant requiring steroids, or azathioprine. ${ }^{8,9)}$ These observations suggest that an altered immune response may play a role in the pathogenesis of the disease. Individuals with diabetes mellitus have a greater frequency and severity of infection. From the earliest reports on studies of adrenocortical function, there has been impressive evidence that adrenocortical hormone, and more specifically cortisol, is essential for normal immunity. Otherwise, prednisone, triamcinolone, dexamethasone and similar commercially popular steroids have the dangerous sideeffect of lowering resistance to infection, which is common to all known glucocorticoids. ${ }^{10)}$ According to previous studies, gram-negative bacteria, particularly Escherichia coli, have been isolated from involved sites of genitourinary malakoplakia in more than two-thirds of patients. ${ }^{11)}$ Bacteria other than yeast were not isolated in the urine culture in the present case with cystitis because the patient was on antibiotic therapy before admission to our hospital. Although we did not carry out a detailed investigation of the patient's immunity, we believe that unilateral renal malakoplakia extending to the perirenal space and the descending colon, as observed in the present case, may result 
from an interaction between various factors such as bacterial infection, impaired host immune response and diminished leukocyte function under the influence of a systemic illness such as secondary adrenal insufficiency and diabetes mellitus.

The common presenting features of malakoplakia of the kidney are high fever, loin tenderness, and a palpable mass with a history of urinary tract infection. ${ }^{8)}$ Based on the reported studies, the degree of decreased kidney function varies up to acute renal failure. $^{12,13)}$

Ultrasound and CT features are variable and only briefly mentioned in many reviews. Features include enlarged kidneys, ${ }^{14)}$ focal hypoechoic renal masses that simulate abscesses ${ }^{15)}$ and heterogeneous masses that calcify, show central areas of necrosis and are mistaken for tumors. ${ }^{16)}$ The imaging appearance of malakoplakia is therefore non-specific, and malignant renal tumor is a common misdiagnosis. The final diagnosis of malakoplakia is usually attained only upon histopathologic examination of the excised specimen.

There is no established treatment for patients with malakoplakia. However, there are treatment options for malakoplakia that include antibiotics, surgical excision, or a combination of both, depending on the site and extent of involvement. Some researchers have suggested that such antibiotics as trimethoprimsulfamethoxazole and ciprofloxacin were beneficial because of their ability to penetrate intracellularly. ${ }^{8,17-20)}$ We started the treatment with ciprofloxacin. During follow-up in the outpatient clinic, we changed the antibiotic treatment to trimethoprimsulfamethoxazole due to the patient's continued complaint of cystitis symptoms.

In conclusion, renal malakoplakia should be taken into account in the differential diagnosis of a patient who presents with urinary tract infection, fever, abdominal pain, and abscesslike lesion in ultrasonography or CT, especially if the patient concerned has diabetes mellitus and a long history of use of exogenous steroids. It is considered that family physicians' early diagnosis would enable prompt treatment and regular monitoring, leading to avoidance of long-term morbidity and mortality.

\section{REFERENCES}

1. Hamodat M, Naghibi B, Yousef GM. Malakoplakia of the neck in a patient with cancer of the colon. Can J Surg 2009;52:E107-8.

2. Kobayashi A, Utsunomiya Y, Kono M, Ito Y, Yamamoto I, Osaka N, et al. Malakoplakia of the kidney. Am J Kidney Dis 2008;51:326-30.

3. Mannan AA, Kahvic M, Singh NG, Abu Sara Y, Bharati C. An unusual case of extensive epididymotesticular malakoplakia in a diabetic patient. Int Urol Nephrol 2010;42:569-73.

4. Michaelis L, Gutmann C. Uber einschlusse in blasentumoren. Z Klin Med 1902;47:208-15.

5. Shabtai M, Anaise D, Frei L, Waltzer WC, Frischer ZI, Jao $S$, et al. Malakoplakia in renal transplantation: an expression of altered tissue reactivity under immunosuppression. Transplant Proc 1989;21:3725-7.

6. van Crevel R, Curfs J, van der Ven AJ, Assmann K, Meis JF, van der Meer JW. Functional and morphological monocyte abnormalities in a patient with malakoplakia. Am J Med 1998; 105:74-7.

7. Hong JJ, Liao PL, Lin JL, Hsueh S, Huang CC. Bilateral renal parenchymal malakoplakia presenting as haemolytic-uraemic syndrome. Nephrol Dial Transplant 1999;14:2206-9.

8. Dobyan DC, Truong LD, Eknoyan G. Renal malacoplakia reappraised. Am J Kidney Dis 1993;22:243-52.

9. Dhabalia JV, Nelivigi GG, Jain NK, Suryavanshi M, Kakkattil S. Malakoplakia of the ureter: an unusual case. Indian J Urol 2008;24:261-2.

10. Jefferies WM. Cortisol and immunity. Med Hypotheses 1991;34:198-208.

11. Yousef GM, Naghibi B, Hamodat MM. Malakoplakia outside the urinary tract. Arch Pathol Lab Med 2007;131:297-300.

12. Albitar S, Genin R, Fen-Chong M, Schohn D, Riviere JP, Serveaux MO, et al. The febrile patient presenting with acute renal failure and enlarged kidneys: another mode of presentation of malakoplakia. Nephrol Dial Transplant 1997;12:1724-6.

13. Tam VK, Kung WH, Li R, Chan KW. Renal parenchymal malacoplakia: a rare cause of ARF with a review of recent literature. Am J Kidney Dis 2003;41:E13-7. 
14. Mitchell MA, Markovitz DM, Killen PD, Braun DK. Bilateral renal parenchymal malacoplakia presenting as fever of unknown origin: case report and review. Clin Infect Dis 1994;18:704-18.

15. Lamb GH, Ayers AB. Ultrasound findings in a case of renal malacoplakia. Br J Radiol 1977;50:753-4.

16. Chen CS, Lai MK, Hsueh S, Hwang TL, Chuang CK. Renal malacoplakia with secondary hepato-duodenal involvement. J Urol 1994;151:982-5.

17. Stanton MJ, Maxted W. Malacoplakia: a study of the literature and current concepts of pathogenesis, diagnosis and
treatment.J Urol 1981;125:139-46.

18. Mokrzycki MH, Yamase H, Kohn OF. Renal malacoplakia with papillary necrosis and renal failure. Am J Kidney Dis 1992;19:587-91.

19. van Furth R, van't Wout JW, Wertheimer PA, Zwartendijk J. Ciprofloxacin for treatment of malakoplakia. Lancet 1992;339:148-9.

20. van der Voort HJ, ten Velden JA, Wassenaar RP, Silberbusch J. Malacoplakia. Two case reports and a comparison of treatment modalities based on a literature review. Arch Intern Med 1996;156:577-83. 